\title{
La infografía de prensa
}

\author{
Dr. José Luis Valero Sancho \\ Facultad de Ciencias de la Comunicación
}

Universidad Autónoma de Barcelona

Artículo fundamentalmente didáctico donde el autor traza unas líneas maestras sobre el significado y utilidad del proceso infográfico aplicado a la prensa. Para ello, repasar las características más relevantes de dicho proceso.

\section{Definición de infografía de prensa}

el intento de una definición de infografía de la prensa diaria aparecen serias dudas, el infoperiodismo y su producto por excelencia la infografía, circunscrita básicamente a la que aparece en periódicos y revistas, s considerada por todos como una de las mejores herramientas para desarrollar y favorecer la supervivencia de la tan traída y llevada crisis de la prensa escrita. Por ello, parece que los profesionales y lectores tienen que ir acostumbrándose cada vez más a este elemento de la cultura visual que poco a poco se va imponiendo en estos medios.

$\mathrm{Ni}$ el vocablo info viene de informática ni grafía viene del concepto de animación que hoy se le pretende dar. Tampoco infografía es lo mismo que información gráfica, puesto que hay otras formas en el periodismo que también lo son.

Tampoco las voces infografía e infográfico, que tan de moda están, figuran todavía en el Diccionario de la Real Academia Española debido a la juventud de ambos conceptos y a la esclerosis de la Academia, que se aprecia también en otros conceptos nuevos que son de dominio público y tardan años en incorporarse de forma general en los diccionarios, cuestión por otro lado comprensible.

Profesionalmente se les llama demasiadas veces gráfico/a: unas veces para abreviar; otras para simplificar su término inglés; otras por desconocimiento de las distintas peculiaridades que tienen; y también por la ambigüedad y amplitud que, a menudo, tiene el término gráfico.

Al referirse a los infográficos, a menudo se piensa en las grandes y complejas infografías colectivas, que podemos llamar megainfografías aunque algunos les llaman megagráficos y tampoco en inglés queda aclarado con the graphics; de 
todas maneras, hay una cierta confusión con este término incluso en libros y tesis doctorales.

Desde que se realizan dibujos informativos ha habido infografías y estos aparecieron en los periódicos, aproximadamente desde hace 200 años, aunque quizá a las primeras se les debería calificar como productos antecedentes, ya que no tenían la componente más inmediata de la información del día debido a las dificultades técnicas que suponía realizar xilografías en el contexto de la impresión tipográfica.

La informática se ha apropiado de este término, pero no nace con la informática, que es únicamente un instrumento (quizá a las sillas u otros objetos dando vueltas en un espacio vacío sin sentido en la pantalla de un ordenador se le debieran llamar productos animáticos) pero tampoco se puede considerar infografía a cualquier combinación de imagen y texto, además no se empleó este término antes de la era informática.

También se usa este término en la publicidad, aunque no se relaciona normalmente con la actualidad y es un producto persuasivo que tiene connotaciones diferentes a las del conocimiento de los acontecimientos. A lo mejor en ese contexto se le podría denominar publigrafía.

Tampoco parece que sea la ilustración, que pretende adornar y no informar, aunque en el contexto de una información textual que emplea una ilustración como fondo, a menudo se confunde con infografía, prescindiendo de que la imagen sea o no informativa.

Quizá estas confusiones se puedan resolver afirmando que una cosa es la infografía general y otra la infografía informativa de prensa, que es un producto del infoperiodismo en cualquiera de los canales, soportes y procesos de fabricación, cuestión que me parece aclaratoria pero también redundante y, desde luego, de mucho mayor interés.

Centrándola en este último sentido, se puede decir con cierta seguridad que la infografía de prensa es una aportación informativa, elaborada en el periódico escrito, realizada con elementos icónicos y tipográficos, que permite o facilita la comprensión de los acontecimientos, acciones o cosas de actualidad o algunos de sus aspectos más significativos y acompaña o sustituye al texto informativo. Se puede también afirmar que existe desde al menos 200 años atrás, pero la informática la ha potenciado mucho. Además puede ser de varios tipos y clases, atendiendo a las necesidades profesionales más diversas, pero esto es otra cuestión que aquí no trataré por su extensión.

Esa es, al menos, una definición que se desprende de diversas consultas realizadas por quien aquí suscribe este texto. En tal sentido he utilizado este término siempre con científicos, intelectuales y profesionales con los que he hablado en distintas ocasiones, con la intención última de definirlo, pero también con la mala fe de que alguien me dijera que ese término no es nada, era otra cosa 
o me lo descalificase. Nadie me ha dicho nada y, a lo sumo, algunos más profanos en el tema me han preguntado sobre el ámbito y la definición, cuando, en realidad, yo les preguntaba a ellos.

\section{Características de la infografía}

La infografía de prensa tiene un total de ocho características peculiares. Estas son:

- Que dé significado a una información plena e independiente.

- Que proporcione la información de actualidad suficiente.

- Que permita comprender el suceso acontecido.

- Que contenga la información escrita con formas tipográficas.

- Que contenga elementos icónicos precisos.

- Que pueda tener capacidad informativa suficiente y sobrada para tener entidad propia o que realice funciones de síntesis o complemento de la información escrita.

- Que proporcione cierta sensación estética, no imprescindible.

- Que no contenga erratas o faltas de concordancia.

Estas características se compilan en dos rasgos esenciales $1^{\circ}$ la infografía es una aportación útil (utilidad) a la comunicación de informaciones en la prensa periódica impresa y $2^{\circ}$ contiene características de visualidad.

\section{Utilidad}

Utilidad es el provecho, conveniencia, interés o fruto que se saca de una cosa, es el grado de significación, información y funcionalidad que puede tener una infografía en el momento en que es editada en un periódico.

Significación en el sentido de que destaca lo más importante de los acontecimientos, acciones o cosas que se tratan en un determinado momento en el contenido informativo de cuestiones conocidas, cercanas y que afectan de alguna manera al lector.

Lo real es lo que tiene existencia significativa o cargada de significado en función del punto de vista desde el que se estudie con una intencionalidad objetiva clara. La realidad es una importante fuente de información para la narración y descripción de un suceso o cosa; sin embargo, no toda la realidad tiene interés para la comunidad, sino únicamente lo más significativo de la misma, y además depende del punto de vista de quien la analiza en un determinado momento ${ }^{1)}$.

(1) Según opinión de Amparo Moreno, catedrática de Periodismo de la Universidad Autónoma de Barcelona, en conversación privada en marzo de 1998 
No interesa toda la realidad significativa. La prensa debe atender especialmente a lo que afecta de manera inmediata y preferente, ya que lo histórico es poco interesante para el presente, que es el objetivo de la prensa diaria y los medios en general, pues del pasado se ocupan en profundidad los historiadores.

También consideramos útil la característica de información entendida como comunicación o adquisición de conocimientos que permiten ampliar o precisar los que se poseen sobre una materia determinada. Es decir, la explicación de circunstancias y detalles de un acontecimiento acción o cosa.

Un periodista desarrolla informaciones que se entienden y las explica de forma comprensible para el lector. Una información es la secuencia de documentos e ideas que se deben ordenar y escribir dando forma a lo que es informe. Información consiste, sobre todo, en convertir en inteligible para el público receptor los datos que muchas veces vienen inconexos y desprovistos de estructura o forma. «Recordamos lo que estima González Requena (1989, 50): Informar es, antes de nada, formalizar, dotar de forma a algo en sí informe y, en cuanto tal, opaco, ininteligible...» ${ }^{(2)}$.

Información es, por tanto, toda sucesión de ideas estructuradas y narradas de manera organizada con un principio periodístico de jerarquía que va de lo importante a lo superfluo y de lo informativo a lo literario. Sin embargo, también es importante conocer qué información se quiere dar a un determinado público lector. No se puede seleccionar nada que no tenga por objeto informar.

La manera normal de escribir una información tiene como soporte y guía un lead que condiciona el contenido principal mediante las cinco preguntas clásicas (con el cómo son seis) ${ }^{(3)}$ del periodismo anglosajón. Si bien no es necesario que la infografía responda a todas, sí son los elementos básicos que componen el eje central de la información en esta clase de comunicaciones. La infografía se debe adaptar a la misma construcción, no entrando en la profundidad del cuerpo central de la información pero sí en los aspectos más importantes de la misma, situados en el mencionado lead ${ }^{(4)}$.

La característica de funcionalidad se entiende en el sentido de que la infografía debe ocupar un papel destacado de servicio al lector, bien sea resumiendo o sintetizando lo más esencial, ampliando complementariamente o sustituyendo al texto de la información.

Si la infografía aparece en la historia de la prensa, al margen de otros aspectos, es como consecuencia de que una idea es difícil de explicar sólo con

2) De Pablos Coello, José Manuel. «La infografía, el nuevo género periodístico». en VV. AA. Estudios sobre tecnologías de la información. Tomo I. Ed. Sanz y Torres. Madrid, 1991, p.156.

(3) Según Martín Vivaldi, el cómo queda situado entre el qué y el por qué, citado por Martínez Albertos, José Luis, en el Curso general de redacción periodística. Editorial Paraninfo. Madrid, 1993.

(4) Mirando de lado el paradigma de Laswell. 
texto y resulta de suma utilidad hacerlo mediante una imagen convenientemente apoyada con breves explicaciones textuales, que resume el texto escrito de la información de forma más visual, sintética y didáctica o aporta elementos informativos nuevos.

La infografía de prensa de gran interés cuando explica un acontecimiento y garantiza su comprensión, sin que sea necesaria una información adicional, pero también puede ser innecesaria cuando no aporta nada nuevo y se solapa con el texto, provocando incluso disfunciones o distorsiones en la explicación de acontecimientos, acciones o cosas.

Más interesantes son cuando se presentan como un extracto que sirve a modo de primera o última lectura, de resumen que facilita la visión de conjunto de la información. En este caso es interesante ver que su uso no es del todo informativo, ya que repite algunos aspectos del texto, pero aporta la síntesis visual, que es un valor añadido. Aporta un resumen o reducción a términos simples y precisos, abreviando lo esencial de un asunto o materia de los textos informativos.

Cuando en una información basta con realizar una infografía, como en el caso de las megainfografías, entonces ésta es muy funcional, pues no se necesita texto escrito, ni título u otros elementos tipográficos que no se encuentren incluidos ya entre sus textos internos.

En definitiva, se aprecian unos rasgos útiles a la comunicación (en diferentes grados) ya que tienen tres características esenciales de la misma, como la información, significación y funcionalidad que a su vez tienen algunas propiedades que no podemos estudiar en este artículo.

\section{Visualidad}

También hay que tener en cuenta que los ojos son una de las vías de entrada de conocimientos más utilizadas por el ser humano, quizá una de las más importantes vías de acceso a la cultura. Pero pueden ser algo más que unos órganos al servicio del hombre, ya que tienen un funcionamiento propio que los hace vulnerables y pueden ser engañados y manipulados desde la apariencia o disposición visual de las cosas.

Visualidad es el efecto agradable de los objetos vistosos que pertenece a la vista. No debemos confundir visual con visualidad, pues el primero es el medio y el segundo el efecto que produce la utilización de los ojos y ésta se desarrolla con la experiencia, ya que consiste en reconocer y percibir algo que antes ha filtrado el órgano de la vista. ¿Cuándo las infografías tienen visualidad? Cuando una información se explica mejor con estos productos icónicos y tipográficos, percibidos por la vista experta y educada de los lectores que les permite recibirlos. «La visualidad es la habilidad de tomar palabras, números y hechos y convertirlos en una pieza de presentación que permita al lector ver los hechos en lugar de leerlos; es como poner las palabras en dibujos con gran claridad; es 
habilidad para conseguir texto + dibujo = 3 (algo más que la simple suma de las partes)»(5)

El ser humano tiene agudeza camaleónica para conocer la realidad, para adaptarse al medio en que se desenvuelve habitualmente. Sin embargo, necesita una cierta capacidad y educación para comprender los mensajes que le llegan. Va adquiriendo experiencia y familiaridad con las imágenes y eso supone todo un aprendizaje y una base para leer mediante un sistema de signos diferentes de los que se aprenden en la escuela donde se enseña mediante códigos verbales literarioz $^{(6)}$.

El lector, ante una infografía, selecciona, según su experiencia, las imágenes o los elementos que le son familiares y le atraen. Busca diferencias, irregularidades o simplemente confirmaciones de lo que ya le es familiar, aunque sea de manera vaga. El ojo actúa selectivamente frente a los impactos visuales. «El espectador debe reencontrar los elementos del pensamiento del diseñador. Con un poco de hábito toma sucesivamente, ante un dibujo, actitudes diversas. Busca las diferencias, los parecidos, un orden, una proporción, los movimientos o, simplemente, busca reconocer algo que ya ha visto» ${ }^{(7)}$ «(...) Entender las cosas fácil y rápidamente, de un vistazo, por complejas que sean» ${ }^{(8)}$.

Determinados elementos gráficos se identifican fácilmente por que se ajustan exactamente a las características de unos cánones de normalidad, perfección, precisión, etc. Son referencias visuales reconocibles por los lectores y los profesionales como, por ejemplo, los símbolos, estereotipos visuales, etc.

Para que tenga lugar este efecto, además de la aportación del lector, es también imprescindible la aportación de la infografía. Ésta debe tener una cierta estética, fácil comprensión, iconografía, tipografía y un tamaño apropiados. Es decir, se debe distinguir el rasgo de visualidad (en diferentes grados y propiedades), porque contiene estas cuatro características importantes.

Iconicidad es el grado de aportación de mensajes figurativos o visuales no codificados, que tienden a representar con signos los diversos objetos, al tiempo que hace inteligible y fácil de reconocer la realidad de los acontecimientos, acciones o cosas que hay en el mundo, sin necesidad de que los lectores se sometan a un aprendizaje previo del significado de esos signos.

El ser humano al nacer comienza a ver el mundo y aprende en su vida y su experiencia a reconocer los objetos que ve y piensa sobre ellos, los toca e

(5) Jonas Dagson, director de infografía del diario IDAG de Gotemburgo (Suecia). Documento de Innovación Periodística $\mathrm{n}^{\circ} 122$. Universidad de Navarra.

Entendiendo por leer a pasar la vista por lo escrito o impreso, pero lo impreso puede ser icónico, no verbal y no escrito.

(7) Bertin, Jacques, en Costa, Joan / Moles, Abraham. Imagen Didáctica,. CEAC S.A.. Barcelona, 1991, p. 174 .

(8) Peltzer, Gonzalo. Periodismo iconográfico. Ediciones Rialp S. A.. Madrid, 1991, p. 12. 
identifica sus funciones. Por ello, al establecer ciertas analogías y representaciones bidimensionales también visuales en dibujos y fotografías, puede entender los mensajes sin necesidad de ese aprendizaje anterior, siempre que convencionalmente se hayan establecido vínculos relacionales de carácter cultural ${ }^{(9)}$.

No podemos considerar como infografía lo que solamente son números o textos sin dibujos de ninguna clase. El límite se lo ponemos en la intención de explicar con dibujos informativos u otras formas icónicas los acontecimientos diarios o alguno de sus aspectos significativos.

En la infografía, la iconicidad es una característica que se encuentra en diversos grados dada la variedad de elementos componentes, pues no se encuentra en el mismo plano un texto que una fotografía y, sin embargo, ambos se encuentran en el mismo análisis.

Una infografía no se concibe sin informaciones escritas, sin una tipografía variada distribuida entre las imágenes, con distintas funciones: unas veces como titulares, otras para describir los distintos elementos gráficos actuando como pie explicativo de fotografía o dibujos, otras como leyendas aclaratorias.

Uno de los textos que no deben faltar en una infografía es el título o elemento mínimo sin el cual no queda presentada y es como si no tuviera puerta de entrada comunicativa. Es un elemento introductor en lo formal y enmarcador del contenido; es su cabeza visible y debe, a su vez, situarse en el interior del recuadro infográfico, generalmente en la parte superior, aunque a veces se encuentra algo camuflado a modo de rótulo.

Otras veces la función del título es la de conducir el contenido, separar los diversas infogramas u ordenar contenidos como en el caso de las tablas, según determinados criterios; otras veces aparecen en las leyendas (siempre que hablamos de texto incluimos los números) para explicar las equivalencias visuales de las tramas, etc.

Los rótulos son textos breves, generalmente de una palabra, que aparecen acompañando a las imágenes; son los nombres de las unidades icónicas más elementales, muy típicos en mapas, gráficos; son necesarios en los dibujos para fijar su identidad de manera que no queden ambigüedades.

El crédito de autor, así como la fuente, es de mucha importancia aunque pueda no parecerlo. Todos los infografistas con los que he hablado coinciden en destacar que las mejores obras se firman y por el contrario hay otras de las que nadie se quiere hacer responsable, bien por su sencillez, bien porque no las consideran propias de profesionales infografistas.

Comprensión es la capacidad para entender y penetrar en el conocimiento de las cosas, es decir, es el entendimiento y la rapidez en la percepción por medio

(9) Eco, Umberto. Tratado de semiótica general. Editorial Lumen. Milán, 1981, p. 325. 
de los sentidos y la inteligencia de las ideas que transmite la infografía, su fácil lectura, etc.

El lector, para poder comprender, como mínimo tiene que poder decodificar los mensajes que se le comunican, tiene que poder verlos adecuadamente. «Una infografía se puede considerar invisible cuando los elementos componentes no se aprecian diferenciados entre sí, no se discriminan» ${ }^{(10)}$. Los signos también pueden ser borrosos por culpa de los defectos graves de imprenta, tanto de preparación como de impresión, pues no se identifican con ninguna cuestión en un determinado contexto; por ello no comunican y no se pueden leer, como en el caso de las letras o signos invertidos, tapados o las llamadas engrasadas que manchan parcialmente las hojas en la impresión por offset.

Además el lector no está acostumbrado a leer esos signos a menudo novedosos y engorrosos en muchas infografías y lo que no puede expresarse icónicamente se debe apoyar mediante leyendas complementarias u otras explicaciones, a menudo lingüísticas, que aclaran y enseñan su significado. La lectura icónica y lingüística primero debe tener visibilidad y legibilidad para el receptor sin ninguna clase de explicaciones adicionales ni ambigüedades que despierten expectativas distintas de las que pretende comunicar el emisor.

Una infografía también puede que no cumpla un cierto requisito estético pero la mejora, a pesar del funcionalismo en el que se pretende enmarcarla; sin embargo, es destacable cualquier elemento gráfico, ilustración o dibujo realizado con cierta dosis de originalidad, belleza, etc., que permite obtener un valor superior de connotaciones.

¿Puede afirmarse que no es infografía cuando se considera que le faltan elementos artísticos o no proporciona sensaciones estéticas? Creo que cuando no tiene estos componentes artísticos y sensaciones estéticas (minusvaloradas, a veces, por profesionales que las consideran innecesarias), también puede dar notables cotas de calidad, ya que el principal cometido es comunicativo, aunque sin esas características pueda no ser una obra de arte, pero tampoco ello es necesario como afirman los mismos profesionales.

Para que pueda darse una impresión sensorial de carácter estético debe haber un objeto artístico que lo provoque. El primer aspecto es el del arte o la componente artística que puede tener la infografía. «El arte es lo que provoca la emoción estética», según Eco, y para Morawski:(11). «He utilizado el término artístico y no estético para subrayar que en mi opinión es el valor compuesto por los artistas tipo concreto y modelo primordial de todo valor estético (...) Artístico se refiere a lo objetivo y estético a lo subjetivo. La creatividad es estética y

(10) Bertin, Jacques. La gráfica y el tratamiento gráfico de la información. Colección Noesis de ComunicaBertin, Jacques. La gráfica y el tratamiento gráfico
ción. Taurus Comunicación. Madrid, 1988, p.259.

(11) Morawski, Stefan. Fundamentos de estética. Ediciones Península. Barcelona 1977, p.20. 
también la recepción o experiencia, mientras que los medios empleados objetivamente son artísticos».

El tamaño, espacio o territorio destinado a la infografía es también uno de los elementos que facilitan la visualidad ya que permite o impide la participación de determinados elementos que facilitan su comprensión y su distribución sin atropellos o congestiones innecesarias. A menudo los profesionales se ponen a favor de disponer de espacio pero también hay quien considera un reto comunicativo el no tenerlo.

En definitiva, ambos rasgos, la utilidad y la visualidad son necesarios en cualquier infografía que se precie. Sin estos, poco valor comunicativo tiene cualquier forma de información gráfica.

\section{Concordancia}

Para concluir, la infografía tiene una característica que se presupone, pero no sirve para valorarla positivamente, y cuyo juicio de calidad se realiza mediante la actitud vigilante sobre su ausencia, es decir en negativo; ésta es la concordancia.

Llamamos concordancia a un conjunto de reglas y elementos mínimos que la infografía no puede dejar de lado en su construcción para uso social. Esas reglas y elementos son tanto los referidos a la coherencia con el idioma, sintaxis y ortografía cn sus respectivas leyes de uso, como con el acontecimiento, acción o cosa en el que se ilustra y con el que tiene que contar para no faltar a la veracidad. Por desconado, también debe ser coherente con la información escrita a la que la infografía acompaña y a la que no puede dejar en entredicho o contradecir. Asimismo tiene que ser fiel a sí misma y no contradecirse internamente.

Como conclusión, la infografía de prensa tiene sus propias características que poco se asemejan a otras formas o productos denominados comúnmente infográficos. Este término utilizado en distintas direcciones de manera anárquica no suscita otra cosa que confusión e imprecisiones, a menudo, de gran calibre. Desde estas líneas reclamo para el César lo que es del César y me ofrezco para ayudar a la consecución de términos apropiados para la clarificación de esta confluencia en la denominación de diversos productos no informativos, si bien me gustaría que se realizaran estudios de cierta envergadura sobre la justificación del término infografía. 